\title{
Polycyclic aromatic hydrocarbons in highway plants and soils. Evidence for a local distillation effect
}

\author{
C. Bryselbout ${ }^{1}$, P. Henner ${ }^{1}$, J. Carsignol ${ }^{2}$ and É. Lichtfouse ${ }^{1 *}$ \\ ${ }^{1}$ Laboratoire Sols et Environnement, INRA-ENSAIA/INPL, BP 172, 54505 Vandouvre-lès-Nancy, France \\ ${ }^{2}$ Centre d'Étude Technique de l'Équipement de l'Est, Technopôle Metz. 2000, BP 5230, 57000 Metz, France \\ * Corresponding author: eric.lichtfouse@ensaia.inpl-nancy.fr
}

Poa trivialis grasses and soils from the side slope of a high-traffic highway were analysed for their PAH content by gas chromatography coupled to mass spectrometry. The ratios of volatile, low-molecular weight PAHs versus high-molecular weight PAHs increase with side slope height. For instance, naphthalene/pyrene values increase from 0.3 to 3.4 in plants. Acenaphthene/fluoranthene values increases from 0.017 to 0.123 in soils. Moreover, soil PAHs can be classified into two categories according to variations of absolute concentrations with height: low-molecular weight PAHs showing an increase and high-molecular weight PAHs showing a decrease. These results demonstrate the occurrence of an atmospheric distillation effect which favour the concentration of high-molecular weight PAHs near the PAH source. Environmental implications of such a phenomenon are discussed. 


\section{Introduction}

Trace levels of polycyclic aromatic hydrocarbons (PAHs) are widely occurring in modern ecosystems [1-4]. Since some PAH members are mutagenic, their presence in plant [1,5-7] is of increasing concern because PAHs may ultimately be transferred to food. Moreover, the presence of PAHs in soils has been correlated with highway traffic and cancer incidence [8]. Nonetheless, despite several reports suggesting that airborne PAHs should be transferred over great distances [9-10], the mechanisms ruling atmospheric transfer are still poorly known. A recent investigation [6] suggests that PAHs should be partitioned between air and plant as a function of ambient temperature. Such an atmospheric distillation process has also been evidenced for organochlorine compounds in snow sampled at increasing height in the mountains of western Canada [11]. Here, we show that a similar process is operating on the side slope of a high-traffic French highway (39000 vehicles per day).

\section{Experimental}

Soils and Poa trivialis grasses were sampled in march 1998 at heights of $2 \mathrm{~m}, 4 \mathrm{~m}$ and $6 \mathrm{~m}$ above road level on the eastern side slope of the A31 highway $30 \mathrm{~km}$ north of Nancy,
France (Fig. 1). At each height, three $1 \mathrm{~kg}$ soil samples were taken $1 \mathrm{~m}$ apart at $0-10 \mathrm{~cm}$ depth, dried at $20^{\circ} \mathrm{C}$, sieved to $2 \mathrm{~mm}$ then mixed. A $100 \mathrm{~g}$ sub-sample was finely ground then sonicated 15 min with $150 \mathrm{ml}$ distilled $\mathrm{CH}_{2} \mathrm{Cl}_{2}$ in $600 \mathrm{ml}$ pyrex beakers (3 times). The $\mathrm{CH}_{2} \mathrm{Cl}_{2}$ extracts were mixed, filtered over $\mathrm{CH}_{2} \mathrm{Cl}_{2}$-prewashed paper filter, concentrated under reduced pressure to about $1 \mathrm{ml}$, transferred into a $2 \mathrm{ml}$ glass vial then allowed to concentrate to dryness under a ventilated hood. A similar procedure was followed for plant sampling $(50 \mathrm{~g})$. Plant samples were mixed, dried at $40{ }^{\circ} \mathrm{C}$ and finely crushed. A $150 \mathrm{mg}$ sub-sample was then extracted with $\mathrm{CH}_{2} \mathrm{Cl}_{2}$ using the pipette Pasteur method [12]. Extracts $(5 \mathrm{mg})$ were fractionated over a Pasteur pipette loaded with $600 \mathrm{mg}$ of $\mathrm{CH}_{2} \mathrm{Cl}_{2}$-prewashed silica-gel then with $150 \mathrm{mg}$ of $\mathrm{CH}_{2} \mathrm{Cl}_{2}$-prewashed Florisil (TLC, Merck). Alkane fractions were eluted with $3 \times 500 \mu$ of $n$-pentane in pre-weighted $2 \mathrm{ml}$ screw-top Varian glass vial. Aromatic fractions were then eluted with $3 \times 500 \mu$ of $n$-pentane$\mathrm{CH}_{2} \mathrm{Cl}_{2}(65 / 35 \mathrm{v} / \mathrm{v})$.

Aromatic fractions were analysed with a Varian Star 3400 gas chromatograph coupled to a Saturn 2000 ion trap mass spectrometer. Conditions: helium pressure 8 psi; autosampler; on column injector; $28 \mathrm{~m} \times 0.25 \mathrm{~mm}$ i.d. fused silica gel column coated with $5 \%$ phenyl-, $95 \%$ methylpolysiloxane phase $(0.25 \mu \mathrm{m}$ thickness $)$; oven temperature: $30{ }^{\circ} \mathrm{C}$ isothermal $1 \mathrm{~min}, 35-110{ }^{\circ} \mathrm{C}$ at $25^{\circ} / \mathrm{min}, 110-300{ }^{\circ} \mathrm{C}$ at $3 \%$ min then $310{ }^{\circ} \mathrm{C}$ isothermal $10 \mathrm{~min}$; EI $70 \mathrm{eV}$, scan 100-300 amu. Calibration was performed on reconstructed

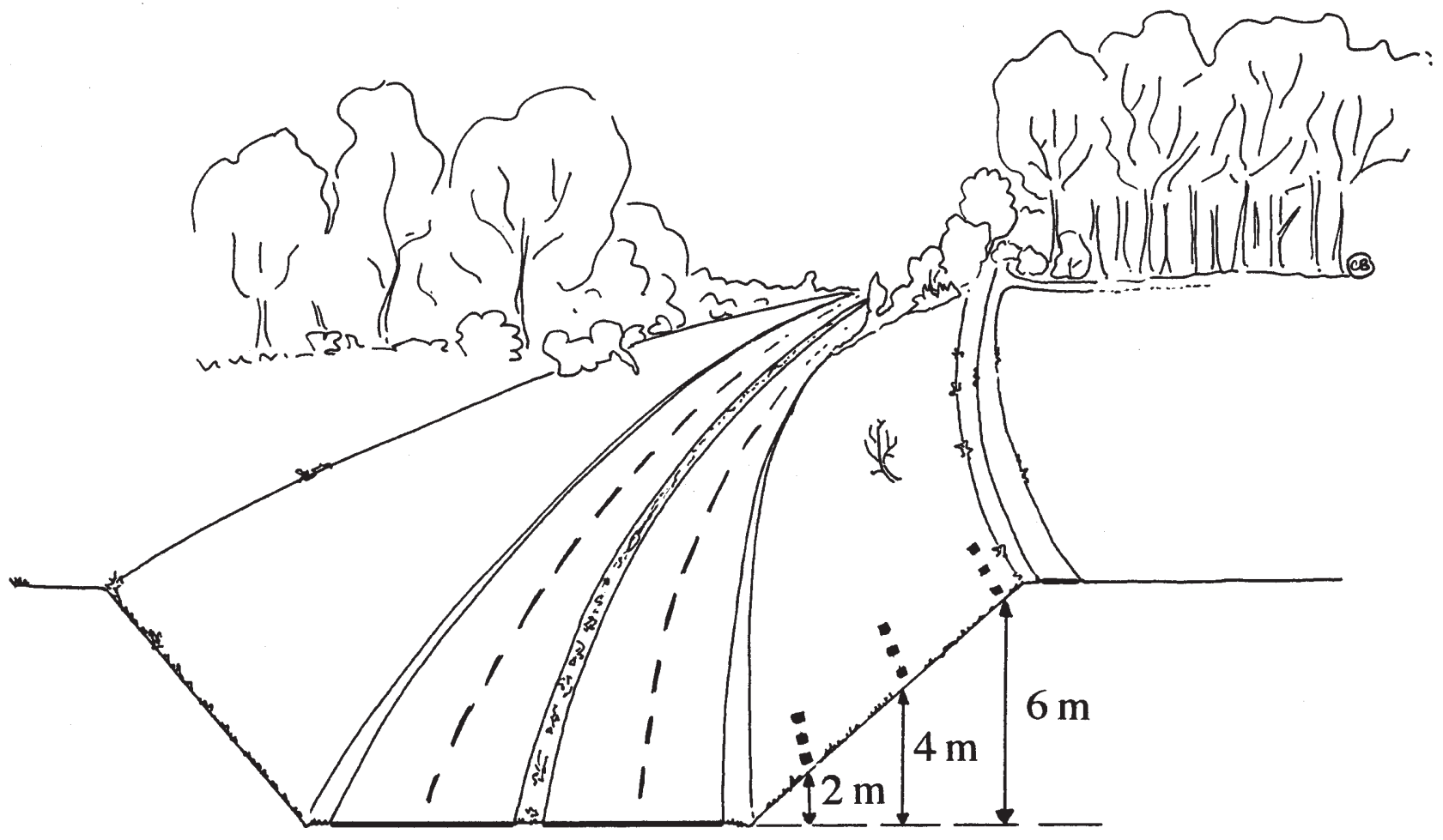

Figure 1. Plant and soil were sampled at increasing height $(2 \mathrm{~m}, 4 \mathrm{~m}$ and $6 \mathrm{~m})$ on the side-slope of a major French highway. 


\section{Plant}

\section{Soil}
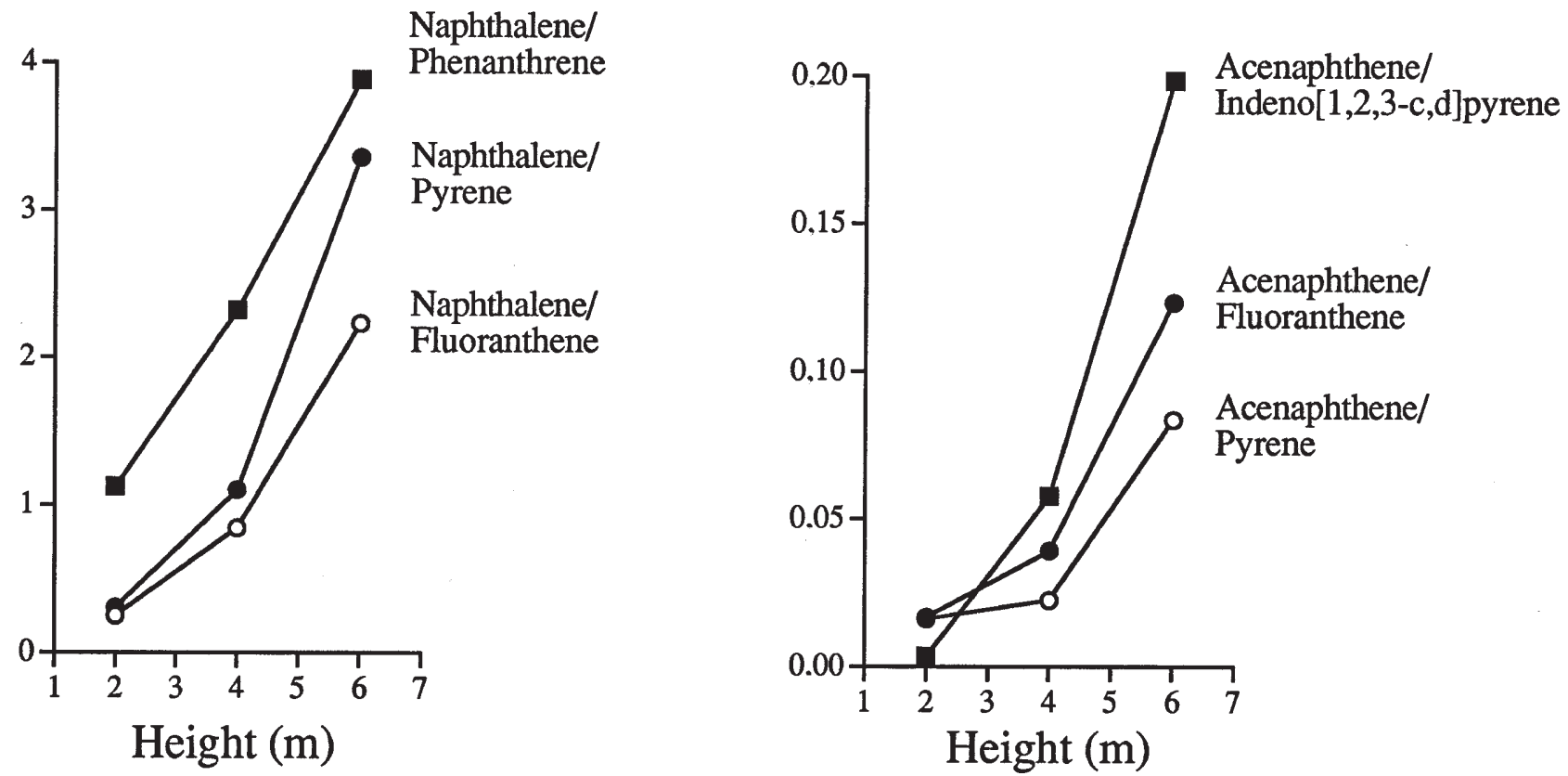

Figure 2. Ratios of low- versus high-molecular PAHs of plant and soil sampled at increasing heights on the side slope of the highway.

Table I. Concentrations of PAHs in $\mathrm{ng} / \mathrm{g}$ dry weight of plants and soils sampled at increasing height. (+) and (-) refers respectively to increases and decreases of concentrations of $6 \mathrm{~m}$ - versus $2 \mathrm{~m}$-samples. nd: not detected.

\begin{tabular}{|c|c|c|c|c|c|c|}
\hline \multirow[b]{2}{*}{ Height } & \multicolumn{3}{|c|}{ PLANT } & \multicolumn{3}{|c|}{ SOIL } \\
\hline & $2 m$ & $4 m$ & $6 m$ & $2 m$ & $4 m$ & $6 m$ \\
\hline Naphthalene & 25 & 65 & $598(+)$ & 3 & 3 & $9(+)$ \\
\hline Acenaphthylene & nd & nd & nd & 75 & 29 & $82(+)$ \\
\hline Acenaphthene & nd & nd & 105 & 149 & 237 & $848(+)$ \\
\hline Fluorene & nd & nd & nd & 949 & 775 & $980(+)$ \\
\hline Phenanthrene & 24 & 28 & $154(+)$ & 2390 & 3075 & $3476(+)$ \\
\hline Anthracene & nd & nd & nd & 809 & 1428 & $1582(+)$ \\
\hline Fluoranthene & 107 & 77 & $268(+)$ & 8851 & 6045 & $6872(-)$ \\
\hline Pyrene & 88 & 59 & $178(+)$ & 9159 & 10464 & $10143(+)$ \\
\hline Benz[a]anthracene + chrysene & 50 & 100 & $158(+)$ & 40371 & 10384 & $18897(-)$ \\
\hline Benzo[b]- + benzo[k]-fluoranthene & nd & nd & nd & 18288 & 3967 & $5770(-)$ \\
\hline Benzo[a]pyrene & nd & nd & nd & 33924 & 6188 & $12421(-)$ \\
\hline Indeno[1,2,3-c,d]pyrene & nd & nd & nd & 41811 & 4114 & $4275(-)$ \\
\hline Benzo[g,h,i]perylene & nd & nd & nd & 36674 & 4414 & $4780(-)$ \\
\hline Dibenz[a,h]enthracene & nd & nd & nd & 8126 & 359 & nd (-) \\
\hline
\end{tabular}


ion current with standard PAH mixtures of naphthalene (m/z 128), acenaphthene (154), acenaphthylene (152), fluorene (166), phenanthrene (178), anthracene (178), fluoranthene (202), pyrene (202), benzo[a]anthracene (228), chrysene (228), benzo[b]- and benzo[k]fluoranthene (252), benzo[a]pyrene (252), indeno[1,2,3-c,d]pyrene (276), benzo[g,h,i]perylene (276) and dibenz[a,h]anthracene (278).

\section{Results and discussion}

\section{Plant PAHs}

Soil and plant were sampled at increasing height on the side slope of a high traffic highway (Fig. 1). PAH concentrations are reported in table I. In Poa trivialis, the relative concentrations of naphthalene versus phenanthrene, fluoranthene and pyrene increase with height (Fig. 2). Since naphthalene is the most volatile compound, this result suggests that PAHs from exhausts are partitioned in the atmosphere above the highway before adsorption on plant waxes. This phenomenon is analogous to the frationation of volatile compounds in a distillation column. Indeed, the partitioning of PAHs should be due to temperature variations [6] from hot engine exhausts to colder air. This distillation effect is confirmed by analysis of soil PAHs as described below.

\section{Soil PAHs}

The 16 EPA PAHs found in soils can be classified into two categories according to their changes of absolute concentrations with height. First, low-molecular weight PAHs such as naphthalene, fluorene and anthracene show a concentration increase from 2 to $6 \mathrm{~m}$ (Tab. I). Second, high-molecular weight PAHs such as benzo[a]pyrene and benzo[g,h,i]perylene show a concentration decrease from 2 to $6 \mathrm{~m}$. These results strengthen the hypothesis of a local distillation effect. Furthermore, the relative concentrations of low-versus highmolecular weight PAHs increase sharply with height, as shown for acenaphthene versus fluoranthene, pyrene and indeno[1,2,3-c.d]pyrene (Fig. 2). A such finding thus confirms the occurrence of a distillation effect around the highway. It is in full agreement with previous studies on vegetation-atmosphere partitioning of PAHs [6].

\section{Environmental implications}

The non-homogeneous transfer of PAHs along highways has several environmental implications. First, the most mutagenic PAHs, e.g. benz[a]pyrene, should be concentrated near the highway. As a consequence, breathing highway atmosphere will increase the health hazards of vehicle drivers. Second, the most carcinogenic PAHs will also concentrate into the rain washings of road surface. We therefore advice to collect these waters in closed systems in order to avoid further contamination of groundwaters. Third, the distillation effect should favour the medium-range transfer of the less mutagenic and most biodegradable PAHs towards plant crops.

\section{Conclusion}

Analysis of PAHs in plants and soils from the side slope of a major highway gives evidence for a local distillation effect. Further studies are in progress to assess the precise origin of PAHs in agronomic plants.

\section{Acknowledgements}

We thank the Centre d'Études Techniques de l'Est for financial support and for a studentship to one of us (CB).

\section{References}

1. Edwards, N. T. J. Environ. Qual. 1983, 12, 427.

2. Lichtfouse, E.; Budzinski, H.; Garrigues, Ph.; Eglinton, T. I. Org. Geochem. 1997, 26, 353.

3. Windsor, J. G.; Hites, R. A. Geochim. Cosmochim. Acta 1979, 43, 27.

4. Jones, K. C.; Straford, J. A.; Tidridge, P.; Waterhouse, K. S.; Johnston, A. E. Environ. Pollut. 1989, 56, 337.

5. Harrison, R. M.; Johnston, W. R. Sci. Tot. Environ. 1985, 46, 121.

6. Simonich, S. L.; Hites, R. A. Environ. Sci. Technol. 1994, 28 , 939.

7. Simonich, S. L.; Hites, R. A. Nature 1994, 370, 49.

8. Blumer, M.; Blumer, W.; Reich, T. Environ. Sci. Technol. 1977, 11, 1082.

9. Blumer, M.; Youngblood, W.W. Science 1975, 188, 53.

10. Sicre, M. A.; Marty, J.-C.; Saliot, A.; Aparicio, X.; Grimalt, J.; Albaiges, J. Atmosph. Environ. 1987, 21, 2247.

11. Blais, J. M.; Schindler, D. W.; Muir, D. C. G.; Kimpe, L. E.; Donald, D. B.; Rosenberg, B. Nature 1998, 395, 585.

12. Henner, P.; Schwartz, C.; Lichtfouse, E. Analusis 1997, 25, M51. 